\title{
PENGARUH KEADILAN ORGANISASIONAL TERHADAP KOMITMEN ORGANISASIONAL DIMEDIASI KEPUASAN KERJA DI PT. JAYA KUSUMA SARANA BALI
}

\author{
Ni Wayan Armiani ${ }^{1}$ \\ Made Surya Putra ${ }^{2}$ \\ ${ }^{1,2}$ Fakultas Ekonomi dan Bisnis Universitas Udayana, Bali, Indonesia \\ email:wayanarmiani1@gmail.com
}

\begin{abstract}
ABSTRAK
Komitmen organisasional merupakan kesediaan orang untuk tetap bertahan di perusahaan. Penelitian ini bertujuan untuk menganalisis pengaruh keadilan organisasional terhadap komitmen organisasional, keadilan organisasional terhadap kepuasan kerja, kepuasan kerja terhadap komitmen organisasional, dan keadilan organisasional terhadap komitmen organisasional melalui mediasi kepuasan kerja. Penelitian ini dilakukan di PT. Jaya Kusuma Sarana Bali. Jumlah sampel yang diambil sebanyak 52 orang karyawan, dengan metode sampling jenuh. Metode pengumpulan data yang digunakan adalah metode wawancara dan kuesioner. Teknik analisis data yang digunakan adalah analisis statistik deskriptif dan analisis Partial Least Square (PLS). Berdasarkan hasil analisis ditemukan bahwa keadilan organisasional berpengaruh positif dan signifikan terhadap komitmen organisasional, keadilan organisasional berpengaruh positif dan signifikan terhadap kepuasan kerja, kepuasan kerja berpengaruh positif dan signifikan terhadap komitmen organisasional, dan kepuasan kerja memediasi parsial pengaruh keadilan organisasional terhadap komitmen organisasional.

Kata kunci: keadilan organisasional; komitmen organisasional; kepuasan kerja
\end{abstract}

\begin{abstract}
Commitment organizational is the willingness of people to stay in the company. This study aims to analyze the influence of organizational justice on organizational commitment, organizational justice on job satisfaction, job satisfaction on organizational commitment, and organizational justice on organizational commitment through job satisfaction mediation. This research was conducted at PT. Jaya Kusuma Sarana Bali. The number of samples were taken 52 employees, with a saturated sampling methods. Data collection methods were used interview and questionnaires methods. The data analysis techniques were used descriptive statistic and Partial Least Square (PLS) analysis. Based on the result of the analysis shows that organizational justice has a positive and significant effect on organizational commitment, organizational justice has a positive and significant effect on job satisfaction, job satisfaction has a positive and significant effect on organizational commitment, and job satisfaction mediates partially the influence of organizational justice on organizational commitment.
\end{abstract}

Keywords: organizational justice; organizational commitment; job satisfaction 


\section{PENDAHULUAN}

Di era globalisasi sekarang ini, persaingan antar perusahaan dalam dunia bisnis semakin ketat. Suatu perusahaan harus mempunyai kekuatan dan kecakapan bersaing yang tinggi, supaya bisa berkompetisi dengan perusahaan pesaing. Hal tersebut diperlukan guna mencapai dan mempertahankan sumber daya yang baik.

Proses mengelola sumber daya manusia perlu dilakukan dengan sebaik mungkin agar perusahaan bisa mencapai tujuan yang diinginkan. Mengelola sumber daya manusia itu sulit karena perusahaan harus dapat meningkatkan komitmen organisasional dari karyawannya. Hal tersebut disebabkan karena komitmen organisasional akan memunculkan ikatan dan merasa turut serta memiliki perusahaan dalam diri karyawan, sehingga mereka akan sanggup berkorban guna menyokong perusahaan dalam memenuhi tujuan-tujuannya dan setia untuk tetap menjadi bagian perusahaan (Ramadhan dan Mujiati, 2018).

Komitmen organisasional memiliki peranan yang penting di dalam organisasi. Komitmen organisasional memiliki peranan penting bagi seorang anggota organisasi untuk membangun kerjasama di dalam organisasi (Asriani dan Supartha, 2017). Komitmen organisasional dibangun atas dasar kepercayaan individu atas nilai-nilai organisasional, kerelaan individu dalam membantu mewujudkan tujuan organisasional dan loyalitas untuk tetap menjadi anggota organisasi (Sentana dan Surya, 2017).

Perusahaan dalam meningkatkan komitmen organisasional karyawannya, perlu mempertimbangkan keadilan organisasionalnya. Keadilan organisasonal adalah persepsi keseluruhan mengenai apa itu keadilan di tempat kerja (Robbins \& Judge, 2015:144). Penelitian mengenai pengaruh keadilan organisasional terhadap komitmen organisasional yang diteliti oleh Rahman et al. (2016), Putra dan Riana (2017), Saputra dan Wibawa (2018), dan Khan et al. (2018) menunjukkan bahwa keadilan organisasional berpengaruh positif dan signifikan terhadap komitmen organisasional. Sementara itu, penelitian yang dilakukan oleh Rejeki dan Wulansari (2015), Ibrahim dan Perez (2014), dan Sancoko dan Panggabean (2015) menyatakan bahwa keadilan organisasional tidak mempunyai pengaruh signifikan terhadap komitmen organisasional.

Karyawan yang memiliki kepuasan kerja yang tinggi dapat meningkatkan komitmen organisasionalnya. Kepuasan kerja merupakan keadaan emosional yang tidak menyenangkan atau menyenangkan bila mana para karyawan memandang pekerjaan mereka (Handoko, 2014:193). Penelitian mengenai pengaruh kepuasan kerja terhadap komitmen organisasional yang diteliti oleh Darsana dan Putra (2017), Ramadhan dan Mujiati (2018), dan Suadnyani dan Netra (2018) menunjukkan bahwa kepuasan kerja berpengaruh positif dan signifikan terhadap komitmen organisasional.

Penelitian mengenai hubungan keadilan organisasional dan kepuasan kerja yang diteliti oleh Hao et al. (2016) dan Indrayani dan Suwandana (2016) menunjukkan bahwa keadilan organisasional memiliki pengaruh yang positif dan signifikan terhadap kepuasan kerja. Hal ini menggambarkan bahwa semakin tinggi keadilan yang dirasakan karyawan maka kepuasan yang dirasakan karyawan turut meningkat. Penelitian yang dilakukan Praditya dan Putra (2016) dan Putra dan Indrawati (2018) mengenai hubungan antara keadilan 
organisasional, kepuasan kerja, dan komitmen organisasional menunjukkan bahwa kepuasan kerja memediasi parsial pengaruh keadilan organisasional terhadap komitmen organisasional.

PT. Jaya Kusuma Sarana Bali adalah sebuah perusahaan kontraktor nasional yang menawarkan jasa pelaksanaan konstruksi. PT. Jaya Kusuma Sarana Bali memiliki kompetensi mengerjakan proyek konstruksi struktural dan arsitektural bangunan komersial. Lokasi dari PT. Jaya Kusuma Sarana Bali yaitu di Jalan Imam Bonjol No. 555 Denpasar.

Berdasarkan hasil wawancara pendahuluan yang dilakukan kepada Ibu Ayu Gek Mirah Lestianingrum selaku HRD PT. Jaya Kusuma Sarana Bali menyatakan tingkat absensi karyawan pada kurun waktu 9 bulan terakhir lumayan tinggi seperti pada bulan September 2018, absensi karyawan PT. Jaya Kusuma Sarana Bali mencapai 4,76 persen (bisa dilihat pada Tabel 1), hal ini berarti karyawan yang melibatkan diri dalam kegiatan perusahaan rendah, sehingga bisa dikatakan bahwa komitmen organisasional karyawan sangat rendah.

Tabel 1.

Data Tingkat Kehadiran Karyawan pada PT. Jaya Kusuma Sarana Bali Bulan Januari- September 2018

\begin{tabular}{|c|c|c|c|c|c|c|c|c|}
\hline Bulan & $\begin{array}{c}\text { Jumlah } \\
\text { Karyawan } \\
\text { (orang) }\end{array}$ & $\begin{array}{c}\text { Jumlah } \\
\text { Hari } \\
\text { Kerja } \\
\text { Per } \\
\text { Bulan } \\
\text { (hari) } \\
\text { (2) }\end{array}$ & & $\begin{array}{c}\text { Jumlah } \\
\text { Iari Kerja } \\
\text { eharusnya } \\
\text { (hari) } \\
(1 \times 2)=3\end{array}$ & $\begin{array}{c}\text { Jumlah } \\
\text { Absens } \\
\text { Per } \\
\text { Bulan } \\
\text { (hari) } \\
\text { (4) }\end{array}$ & $\begin{array}{r}\text { H } \\
\text { Ses } \\
\end{array}$ & $\begin{array}{c}\text { Jumlah } \\
\text { Hari Kerja } \\
\text { esungguhnya } \\
\text { (hari) } \\
(3-4)=(5)\end{array}$ & $\begin{array}{c}\text { Persentase } \\
\text { Absensi }\end{array}$ \\
\hline Januari & 63 & 26 & & 1.636 & 72 & & 1.564 & 4,40 \\
\hline Februari & 62 & 23 & & 1.426 & 49 & & 1.377 & 3,43 \\
\hline Maret & 55 & 23 & & 1.265 & 52 & & 1.213 & 4,11 \\
\hline April & 53 & 24 & & 1.272 & 36 & & 1.236 & 2,83 \\
\hline Mei & 53 & 23 & & 1.219 & 45 & & 1.174 & 3,69 \\
\hline Juni & 53 & 21 & & 1.113 & 59 & & 1.054 & 5,30 \\
\hline Juli & 53 & 26 & & 1.378 & 50 & & 1.328 & 3,62 \\
\hline Agustus & 50 & 25 & & 1.250 & 46 & & 1.204 & 3,68 \\
\hline September & 49 & 24 & & 1.176 & 56 & & 1.120 & 4,76 \\
\hline Total & & & 215 & & & 515 & 11.27 & 35,82 \\
\hline Rata-rata & 54 & & 23,89 & 1.30 & & 57,22 & $1.252,2$ & 3,98 \\
\hline
\end{tabular}

Sumber : HRD PT. Jaya Kusuma Sarana Bali, 2018

Hasil perhitungan tingkat absensi karyawan PT. Jaya Kusuma Sarana Bali menunjukkan bahwa rata-rata tingkat absensi karyawan sebesar 3,98 persen, ini berarti bahwa disiplin karyawan sangat buruk.

Ketika karyawan diperlakukan tidak adil oleh perusahaan, maka bisa berdampak pada meningkatnya absensi. Selain itu, apabila tingkat kepuasan kerja karyawan rendah maka tingkat kemangkirannya cenderung tinggi. Hubungan tingkat absensi dengan keadilan organisasional, kepuasan kerja, dan komitmen 
organisasional yaitu tingkat absensi karyawan bisa disebabkan oleh keadilan organisasional dan kepuasan kerja yang rendah sehingga komitmen organisasional menjadi rendah pula untuk melibatkan diri dalam kegiatan dan pencapaian tujuan perusahaan.

Tabel 2.

Jumlah Promosi Karyawan PT. Jaya Kusuma Sarana Bali Tahun 2016- 2018

\begin{tabular}{cccc}
\hline No. & Tahun & Jumlah Promosi (orang) & Jumlah Karyawan (orang) \\
\hline 1 & 2016 & 0 & 112 \\
2 & 2017 & 3 & 79 \\
3 & 2018 & 1 & 52 \\
\hline
\end{tabular}

Wawancara dilakukan kepada karyawan PT. Jaya Kusuma Sarana Bali yang menyatakan bahwa jarang adanya promosi jabatan. Hal tersebut bisa dilihat pada Tabel 2 data jumlah promosi karyawan PT. Jaya Kusuma Sarana Bali tahun 20162018. Tahun 2016 tidak adanya promosi jabatan, tahun 2017 karyawan yang dipromosikan sebanyak 3 orang, dan tahun 2018 karyawan yang dipromosikan sebanyak 1 orang. Hasil perhitungan jumlah promosi karyawan PT. Jaya Kusuma Sarana Bali menunjukkan bahwa jumlah promosi karyawan rendah. Hubungan jumlah promosi karyawan dengan komitmen organisasional bermakna semakin rendah jumlah promosi karyawan bisa menjadi penyebab komitmen organisasional yang rendah. Hal ini berarti apabila karyawan mempunyai tingkat kepuasan kerja yang rendah terhadap pekerjaannya maka akan memicu terjadinya komitmen organisasional yang rendah.

Rumusan masalah dalam penelitian ini adalah sebagai berikut. 1) Bagaimanakah pengaruh keadilan organisasional terhadap komitmen organisasional di PT. Jaya Kusuma Sarana Bali 2) Bagaimanakah pengaruh keadilan organisasional terhadap kepuasan kerja di PT. Jaya Kusuma Sarana Bali? 3) Bagaimanakah pengaruh kepuasan kerja terhadap komitmen organisasional di PT. Jaya Kusuma Sarana Bali? 4) Bagaimanakah pengaruh keadilan organisasional terhadap komitmen organisasional melalui mediasi kepuasan kerja di PT. Jaya Kusuma Sarana Bali?

Tujuan dari penelitian ini adalah sebagai berikut. 1) Untuk menganalisis pengaruh keadilan organisasional terhadap komitmen organisasional di PT. Jaya Kusuma Sarana Bali. 2) Untuk menganalisis pengaruh keadilan organisasional terhadap kepuasan kerja di PT. Jaya Kusuma Sarana Bali. 3) Untuk menganalisis pengaruh kepuasan kerja terhadap komitmen organisasional di PT. Jaya Kusuma Sarana Bali. 4) Untuk menganalisis pengaruh keadilan organisasional terhadap komitmen organisasional melalui mediasi kepuasan kerja di PT. Jaya Kusuma Sarana Bali.

Manfaat dari penelitian ini adalah sebagai berikut. 1) Manfaat teoritis, hasil penelitian ini diharapkan dapat digunakan untuk menambah bukti empiris pada Manajemen Sumber Daya Manusia khususnya tentang keadilan organisasional, komitmen organisasional, dan kepuasan kerja. 2) Manfaat praktis, hasil penelitian 
ini diharapkan bisa menjadi masukan bagi pihak manajemen di perusahaan dalam membuat kebijakan Manajemen Sumber Daya Manusia terkait dengan keadilan organisasional, komitmen organisasional, dan kepuasan kerja.

Robbins dan Judge (2015:47) menyatakan bahwa komitmen organisasional adalah tingkat dimana seorang pekerja mengidentifikasi sebuah organisasi, tujuan dan harapannya untuk tetap menjadi anggota. Komitmen organisasional mempunyai tiga dimensi yaitu komitmen afektif, komitmen berkelanjutan, dan komitmen normatif.

Keadilan organisasional adalah persepsi keadilan yang dirasakan terhadap proses perusahaan selama pemberian kompensasi dan pengambilan keputusan serta cara memperlakukan karyawan dengan bermartabat, memberi perhatian, dan hormat (Mada dkk., 2017). Keadilan organisasional mempunyai tiga dimensi antara lain keadilan distributif, keadilan prosedural, dan keadilan interaksional.

Herzberg (1959) menyatakan bahwa Two Factor Theory adalah teori yang membagi faktor-faktor penyebab kepuasan kerja. Faktor motivasi (motivators) ini merupakan faktor intrinsik yang terdiri dari prestasi, pengakuan, pekerjaan itu sendiri, tanggung jawab, kemajuan, dan kemungkinan berkembang. Hygiene factor ini merupakan faktor ekstrinsik pekerjaan yang terdiri dari kebijaksanaan dan administrasi perusahaan, pengawasan, gaji, hubungan antarpribadi dengan rekan kerja, atasan, dan bawahan, kondisi pekerjaan, keamanan pekerjaan dan status.

Kepuasan kerja merupakan suatu cara pandang seseorang baik yang bersifat positif maupun bersifat negatif tentang pekerjaannya (Siagian, 2016:295). Kepuasan kerja mempunyai lima dimensi yaitu kepuasan terhadap atasan, kepuasan terhadap rekan kerja, kepuasan terhadap gaji, kepuasan terhadap promosi, dan kepuasan terhadap pekerjaan itu sendiri.

Penelitian tentang hubungan keadilan organisasional terhadap komitmen organisasional yang dilaksanakan oleh Imran et al. (2015), Lashari et al. (2016), Mensah et al. (2016), Rahman et al. (2016), Putra dan Riana (2017), Hutagalung dan Wibawa (2018), dan Khan et al. (2018) menunjukkan dimana keadilan organisasional memiliki pengaruh yang positif dan signifikan pada komitmen organisasional. Berdasarkan hasil di atas, maka dapat dirumuskan hipotesis sebagai berikut:

$\mathrm{H}_{1}$ : Keadilan organisasional berpengaruh positif dan signifikan terhadap

komitmen organisasional.

Penelitian mengenai hubungan keadilan organisasional dan kepuasan kerja yang diteliti oleh Altahayneh et al. (2014), Totawar dan Nambudiri (2014), Naeem et al. (2014), Hao et al. (2016), Kristanto dkk. (2014), dan Indrayani dan Suwandana (2016) menunjukkan bahwa keadilan organisasional berpengaruh positif dan signifikan terhadap kepuasan kerja. Berdasarkan hasil dari penelitianpenelitian di atas, maka dapat dirumuskan hipotesis sebagai berikut: 
$\mathrm{H}_{2}$ : Keadilan organisasional berpengaruh positif dan signifikan terhadap kepuasan kerja.

Penelitian mengenai pengaruh kepuasan kerja terhadap komitmen organisasional yang diteliti oleh Mohamed dan Shurbagi (2014), Awais et al. (2015), Tarigan dan Ariani (2015), Darsana dan Putra (2017), Kerisna dan Suana (2017), Yanti dan Dahlan (2017), Saputra dan Wibawa (2018), Ramadhan dan Mujiati (2018), dan Suadnyani dan Netra (2018) menunjukkan bahwa kepuasan kerja berpengaruh positif dan signifikan terhadap komitmen organisasional. Berdasarkan hasil dari penelitian-penelitian di atas, maka dapat dirumuskan hipotesis sebagai berikut:

$\mathrm{H}_{3}$ : Kepuasan kerja berpengaruh positif dan signifikan terhadap komitmen organisasional.

Penelitian yang dilakukan Praditya dan Putra (2016), Putra dan Indrawati (2018), dan Karakus et al. (2014) mengenai hubungan antara keadilan organisasional, kepuasan kerja, dan komitmen organisasional menunjukkan bahwa kepuasan kerja memediasi parsial pengaruh keadilan organisasional terhadap komitmen organisasional. Berdasarkan hasil dari penelitian-penelitian di atas, maka dapat dirumuskan hipotesis sebagai berikut:

$\mathrm{H}_{4}$ : Kepuasan kerja memediasi parsial pengaruh keadilan organisasional terhadap komitmen organisasional.

\section{METODE PENELITIAN}

Desain penelitian ini digolongkan pada jenis penelitian asosiatif (hubungan). Penelitian ini dilakukan di PT. Jaya Kusuma Sarana Bali yang berlokasi di Jalan Imam Bonjol No. 555 Denpasar. Obyek yang digunakan adalah Keadilan Organisasional, Komitmen Organisasional, dan Kepuasan Kerja. Variabel endogen dua $\left(\eta_{2}\right)$ yaitu komitmen organisasional. Variabel eksogen $\left(\xi_{1}\right)$ yaitu keadilan organisasional. Variabel endogen satu $\left(\eta_{1}\right)$ yaitu kepuasan kerja.

Data kuantitatif dalam penelitian ini adalah tingkat kehadiran karyawan, jumlah karyawan PT. Jaya Kusuma Sarana Bali, dan hasil berupa skor dari jawaban kuisioner. Data kualitatif dari penelitian ini adalah sejarah berdirinya perusahaan, struktur organisasi, dan tanggapan responden yang menjawab dalam kuesioner yang telah disebarkan. Sumber primer dalam penelitian ini adalah melalui wawancara kepada HRD dan karyawan PT. Jaya Kusuma Sarana Bali serta hasil kuesioner yang telah disebarkan kepada karyawan PT. Jaya Kusuma Sarana Bali. Sumber sekunder dalam penelitian ini diperoleh dari PT. Jaya Kusuma Sarana Bali berdasarkan dokumen-dokumen yang sudah ada.

Skala Likert digunakan untuk mengukur sikap, pendapat, dan persepsi seseorang atau sekelompok orang tentang fenomena sosial (Sugiyono, 2017:158). Uji validitas digunakan untuk mengukur sah atau valid tidaknya suatu kuesioner (Ghozali, 2016:52). Instrumen dikatakan valid apabila koefisien korelasinya di atas 0,30. Uji reliabilitas sebenarnya adalah alat untuk mengukur suatu kuisioner yang merupakan indikator variabel atau konstruk (Ghozali, 2016:47). Instrumen dikatakan reliabel apabila memiliki nilai Cronbach's Alpha lebih besar dari 0,60. 
Populasi dalam penelitian ini adalah seluruh karyawan PT. Jaya Kusuma Sarana Bali yang berjumlah 52 orang. Sampel dalam penelitian ini berjumlah 52 orang. Metode penentuan sampel yang digunakan dalam penelitian ini adalah sampling jenuh atau sensus, sebab seluruh anggota populasi dijadikan sampel. Metode pengumpulan data yang digunakan dalam penelitian ini adalah metode wawancara dan kuesioner.

Teknik analisis data penelitian ini menggunakan statistik deskriptif dan statistik inferensial. Statistik deskriptif dalam penelitian ini digunakan untuk mendeskripsikan karakteristik responden dan uraian tentang skor jawaban responden di dalam kuesioner. Statistik inferensial yang dipakai dalam penelitian ini yaitu analisis Partial Least Square (PLS).

Pengujian variabel mediasi dilakukan dengan memakai metode Hair et al. (2010). Metode ini terdiri atas empat langkah yaitu memeriksa efek keadilan organisasional terhadap komitmen organisasional pada model dengan melibatkan kepuasan kerja (efek A), efek keadilan organisasional terhadap komitmen organisasional pada model tanpa melibatkan kepuasan kerja (efek B), efek keadilan organisasional terhadap kepuasan kerja pada model (efek C), dan efek kepuasan kerja terhadap komitmen organisasional pada model (efek D).

\section{HASIL DAN PEMBAHASAN}

Berdasarkan hasil penelitian yang diterapkan pada karyawan PT. Jaya Kusuma Sarana Bali dapat diketahui karakteristik responden dijelaskan pada Tabel 3. sebagai berikut :

Tabel 3.

Karakteristik Responden

\begin{tabular}{|c|c|c|c|c|}
\hline No. & Variabel & Klasifikasi & $\begin{array}{l}\text { Jumlah } \\
\text { (orang) }\end{array}$ & Persentase \\
\hline \multirow[t]{3}{*}{1.} & Jenis Kelamin & Laki-laki & 42 & 81 \\
\hline & & Perempuan & 10 & 19 \\
\hline & Jumlah & & 52 & 100 \\
\hline \multirow[t]{5}{*}{2.} & Usia & 21-30 tahun & 7 & 13,5 \\
\hline & & $31-40$ tahun & 20 & 38,5 \\
\hline & & 41-50 tahun & 17 & 33 \\
\hline & & $>50$ tahun & 8 & 15 \\
\hline & Jumlah & & 52 & 100 \\
\hline \multirow[t]{5}{*}{3.} & Pendidikan Terakhir & SMP & 2 & 4 \\
\hline & & SMA & 20 & 38 \\
\hline & & D3 & 3 & 6 \\
\hline & & S1 & 26 & 50 \\
\hline & & $\mathrm{S} 2$ & 1 & 2 \\
\hline
\end{tabular}

Bersambung.... 
Lanjutan Tabel 3.

\begin{tabular}{|c|c|c|c|c|}
\hline No. & Variabel & Klasifikasi & $\begin{array}{l}\text { Jumlah } \\
\text { (orang) }\end{array}$ & Persentase \\
\hline \multicolumn{3}{|c|}{ Jumlah } & 52 & 100 \\
\hline \multirow[t]{3}{*}{4.} & Masa Kerja & $1-5$ tahun & 12 & 23 \\
\hline & & 6-10 tahun & 17 & 33 \\
\hline & & $11-15$ tahun & 11 & 21 \\
\hline 5. & Masa Kerja & $16-20$ tahun & 12 & 23 \\
\hline \multicolumn{3}{|c|}{ Jumlah } & 52 & 100 \\
\hline
\end{tabular}

Sumber : Data primer diolah, 2018

Tabel 3. menunjukkan bahwa karyawan laki-laki lebih banyak daripada perempuan yang bekerja di PT. Jaya Kusuma Sarana Bali karena tenaga karyawan laki-laki lebih dibutuhkan dalam menyelesaikan pekerjaan berat yang ditugaskan perusahaan. Perusahaan masih memberi kesempatan pada karyawan yang berusia $>50$ tahun untuk bekerja di perusahaan. Karyawan dengan tingkat pendidikan S1 lebih banyak dibandingkan karyawan yang memiliki tingkat pendidikan SMP, SMA/SMK, dan D3, hal ini menunjukkan bahwa perusahaan membagi komposisi karyawan dengan seimbang. Masa kerja karyawan erat kaitannya dengan usia pensiun, dimana masih ada karyawan yang bekerja pada usia $>50$ tahun padahal usia pensiun di perusahaan swasta umumnya pada usia 50 atau 55 tahun.

Hasil uji validitas memperlihatkan bahwa semua variabel mempunyai nilai koefisien korelasi dengan skor total semua item pertanyaan lebih besar dari 0,30. Hal ini berarti butir-butir pertanyaan dalam instrumen penelitian tersebut valid.

Tabel 4.

Uji Reliabilitas

\begin{tabular}{lcc}
\hline \multicolumn{1}{c}{ Variabel } & Cronbach's Alpha & Keterangan \\
\hline Komitmen Organisasional $(\eta 2)$ & 0,762 & Reliabel \\
Keadilan Organisasional $(\xi 1)$ & 0,766 & Reliabel \\
Kepuasan Kerja $(\eta 1)$ & 0,769 & Reliabel \\
\hline
\end{tabular}

Sumber : Data primer diolah, 2018

Hasil pengujian tingkat reliabilitas yang ditunjukkan dalam Tabel 4. dimana semua instrumen mempunyai koefisien Cronbach's Alpha melebihi 0,60. Hal tersebut menunjukkan semua instrumen dapat dikatakan reliabel dan instrumen layak dipakai dalam penelitian.

Variabel komitmen organisasional masuk dalam kategori tinggi karena memiliki nilai rata-rata 3,90. Hal ini berarti sebagian besar karyawan PT. Jaya Kusuma Sarana Bali sudah memiliki komitmen organisasional yang tinggi. Variabel keadilan organisasional masuk dalam kategori tinggi karena memiliki nilai rata-rata 3,99. Hal ini berarti sebagian besar karyawan PT. Jaya Kusuma Sarana Bali sudah memiliki keadilan organisasional yang tinggi. Variabel 
Ni Wayan Armiani, Pengaruh Keadilan Organisasional...

kepuasan kerja masuk dalam kategori tinggi karena memiliki nilai rata-rata 3,91. Hal ini berarti sebagian besar karyawan PT. Jaya Kusuma Sarana Bali sudah memiliki kepuasan kerja yang tinggi.

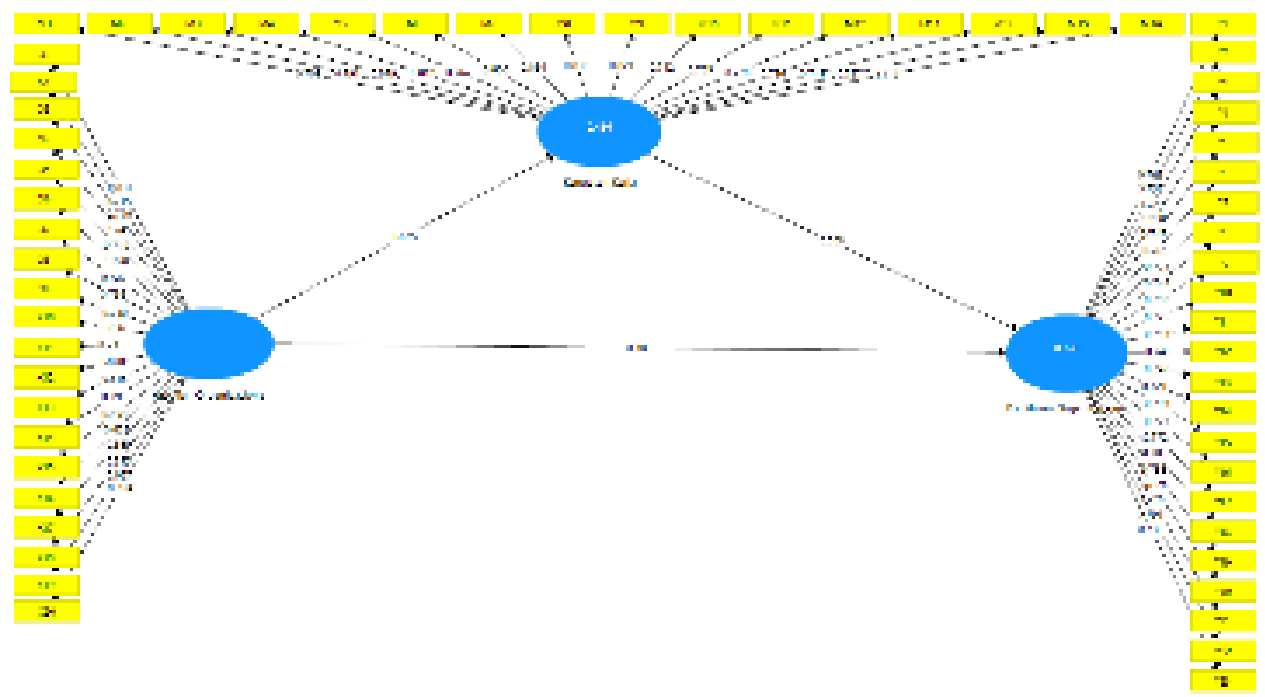

Gambar 1. Outer Model

Sumber: Data primer diolah, 2018

Secara lebih rinci, hasil Uji Partial Least Square (PLS) bisa diamati pada tabel berikut.

Tabel 5.

Nilai Loadings

\begin{tabular}{|c|c|c|c|c|}
\hline Indikator & Keadilan Org. & $\begin{array}{c}\text { Kepuasan } \\
\text { Kerja }\end{array}$ & Komitmen Org. & Keterangan \\
\hline $\mathrm{X} 11$ & 0,837 & & & Valid \\
\hline $\mathrm{X} 12$ & 0,715 & & & Valid \\
\hline $\mathrm{X} 13$ & 0,779 & & & Valid \\
\hline X14 & 0,745 & & & Valid \\
\hline $\mathrm{X} 15$ & 0,719 & & & Valid \\
\hline $\mathrm{X} 16$ & 0,728 & & & Valid \\
\hline X17 & 0,729 & & & Valid \\
\hline $\mathrm{X} 18$ & 0,786 & & & Valid \\
\hline X19 & 0,730 & & & Valid \\
\hline $\mathrm{X} 20$ & 0,706 & & & Valid \\
\hline $\mathrm{X} 21$ & 0,733 & & & Valid \\
\hline $\mathrm{X} 22$ & 0,870 & & & Valid \\
\hline $\mathrm{X} 23$ & 0,815 & & & Valid \\
\hline $\mathrm{X} 24$ & 0,798 & & & Valid \\
\hline $\mathrm{X} 25$ & 0,853 & & & Valid \\
\hline $\mathrm{X} 26$ & 0,822 & & & Valid \\
\hline
\end{tabular}

bersambung... 
E-Jurnal Manajemen, Vol. 8, No. 11, 2019 : 6388-6407

lanjutan Tabel 5.

\begin{tabular}{|c|c|c|c|c|}
\hline Indikator & Keadilan Org. & $\begin{array}{c}\text { Kepuasan } \\
\text { Kerja }\end{array}$ & Komitmen Org. & Keterangan \\
\hline $\mathrm{X} 27$ & 0,869 & & & Valid \\
\hline $\mathrm{X} 28$ & 0,893 & & & Valid \\
\hline $\mathrm{X} 29$ & 0,867 & & & Valid \\
\hline $\mathrm{X} 30$ & 0,774 & & & Valid \\
\hline Y11 & & 0,709 & & Valid \\
\hline Y12 & & 0,791 & & Valid \\
\hline Y13 & & 0,879 & & Valid \\
\hline Y14 & & 0,812 & & Valid \\
\hline Y15 & & 0,767 & & Valid \\
\hline Y16 & & 0,800 & & Valid \\
\hline Y17 & & 0,834 & & Valid \\
\hline Y18 & & 0,832 & & Valid \\
\hline Y19 & & 0,821 & & Valid \\
\hline Y20 & & 0,742 & & Valid \\
\hline Y21 & & 0,789 & & Valid \\
\hline Y22 & & 0,770 & & Valid \\
\hline Y23 & & 0,726 & & Valid \\
\hline Y24 & & 0,749 & & Valid \\
\hline Y25 & & 0,727 & & Valid \\
\hline Y26 & & 0,717 & & Valid \\
\hline Y21 & & & 0,762 & Valid \\
\hline Y22 & & & 0,753 & Valid \\
\hline Y23 & & & 0,729 & Valid \\
\hline Y24 & & & 0,758 & Valid \\
\hline Y25 & & & 0,747 & Valid \\
\hline Y26 & & & 0,761 & Valid \\
\hline Y27 & & & 0,778 & Valid \\
\hline Y28 & & & 0,743 & Valid \\
\hline Y29 & & & 0,792 & Valid \\
\hline Y30 & & & 0,725 & Valid \\
\hline Y31 & & & 0,713 & Valid \\
\hline Y32 & & & 0,748 & Valid \\
\hline Y33 & & & 0,748 & Valid \\
\hline Y34 & & & 0,721 & Valid \\
\hline Y35 & & & 0,793 & Valid \\
\hline Y36 & & & 0,727 & Valid \\
\hline Y37 & & & 0,772 & Valid \\
\hline Y38 & & & 0,709 & Valid \\
\hline Y39 & & & 0,756 & Valid \\
\hline Y40 & & & 0,709 & Valid \\
\hline Y41 & & & 0,726 & Valid \\
\hline Y42 & & & 0,791 & Valid \\
\hline Y43 & & & 0,732 & Valid \\
\hline
\end{tabular}

Sumber : Data primer diolah, 2018

Berdasarkan Tabel 5. pengujian convergent validity memperlihatkan besarnya loading faktor indikator keadilan organisasional, kepuasan kerja, dan 
Ni Wayan Armiani, Pengaruh Keadilan Organisasional...

komitmen organisasional berada di atas 0,50 yang memiliki arti keseluruhan indikator keadilan organisasional, kepuasan kerja, dan komitmen organisasional dinyatakan valid.

Tabel 6.

Cross Loadings

\begin{tabular}{|c|c|c|c|c|}
\hline Indikator & Keadilan Org. & $\begin{array}{c}\text { Kepuasan } \\
\text { Kerja }\end{array}$ & Komitmen Org. & Keterangan \\
\hline X11 & 0,837 & 0,602 & 0,615 & Valid \\
\hline $\mathrm{X} 12$ & 0,715 & 0,544 & 0,631 & Valid \\
\hline X13 & 0,779 & 0,584 & 0,561 & Valid \\
\hline X14 & 0,745 & 0,502 & 0,540 & Valid \\
\hline X15 & 0,719 & 0,492 & 0,621 & Valid \\
\hline X16 & 0,728 & 0,499 & 0,593 & Valid \\
\hline $\mathrm{X} 17$ & 0,729 & 0,475 & 0,545 & Valid \\
\hline X18 & 0,786 & 0,563 & 0,587 & Valid \\
\hline X19 & 0,730 & 0,463 & 0,467 & Valid \\
\hline $\mathrm{X} 20$ & 0,706 & 0,546 & 0,642 & Valid \\
\hline $\mathrm{X} 21$ & 0,733 & 0,564 & 0,599 & Valid \\
\hline $\mathrm{X} 22$ & 0,870 & 0,538 & 0,632 & Valid \\
\hline $\mathrm{X} 23$ & 0,815 & 0,456 & 0,534 & Valid \\
\hline X24 & 0,798 & 0,503 & 0,635 & Valid \\
\hline X25 & 0,853 & 0,485 & 0,571 & Valid \\
\hline X26 & 0,822 & 0,564 & 0,626 & Valid \\
\hline $\mathrm{X} 27$ & 0,869 & 0,586 & 0,634 & Valid \\
\hline X28 & 0,893 & 0,611 & 0,683 & Valid \\
\hline X29 & 0,867 & 0,549 & 0,605 & Valid \\
\hline X30 & 0,774 & 0,479 & 0,594 & Valid \\
\hline Y11 & 0,490 & 0,709 & 0,495 & Valid \\
\hline Y12 & 0,545 & 0,791 & 0,771 & Valid \\
\hline Y13 & 0,654 & 0,879 & 0,676 & Valid \\
\hline Y14 & 0,521 & 0,812 & 0,607 & Valid \\
\hline Y15 & 0,589 & 0,767 & 0,621 & Valid \\
\hline Y16 & 0,498 & $\mathbf{0 , 8 0 0}$ & 0,617 & Valid \\
\hline Y17 & 0,615 & $\mathbf{0 , 8 3 4}$ & 0,651 & Valid \\
\hline Y18 & 0,625 & $\mathbf{0 , 8 3 2}$ & 0,697 & Valid \\
\hline Y19 & 0,610 & 0,821 & 0,644 & Valid \\
\hline Y20 & 0,432 & 0,742 & 0,703 & Valid \\
\hline Y21 & 0,442 & 0,789 & 0,736 & Valid \\
\hline Y22 & 0,556 & 0,770 & 0,698 & Valid \\
\hline Y23 & 0,426 & 0,726 & 0,516 & Valid \\
\hline Y24 & 0,443 & 0,749 & 0,601 & Valid \\
\hline Y25 & 0,319 & 0,727 & 0,459 & Valid \\
\hline Y26 & 0,545 & 0,717 & 0,592 & Valid \\
\hline Y18 & 0,625 & $\mathbf{0 , 8 3 2}$ & 0,697 & Valid \\
\hline Y19 & 0,610 & 0,821 & 0,644 & Valid \\
\hline Y20 & 0,432 & 0,742 & 0,703 & Valid \\
\hline Y21 & 0,442 & 0,789 & 0,736 & Valid \\
\hline Y22 & 0,556 & 0,770 & 0,698 & Valid \\
\hline Y23 & 0,426 & 0,726 & 0,516 & Valid \\
\hline
\end{tabular}

bersambung... 
lanjutan Tabel 6.

\begin{tabular}{ccccc}
\hline Indikator & Keadilan Org. & $\begin{array}{c}\text { Kepuasan } \\
\text { Kerja }\end{array}$ & Komitmen Org. & Keterangan \\
\hline Y24 & 0,443 & $\mathbf{0 , 7 4 9}$ & 0,601 & Valid \\
Y25 & 0,319 & $\mathbf{0 , 7 2 7}$ & 0,459 & Valid \\
Y26 & 0,545 & $\mathbf{0 , 7 1 7}$ & 0,592 & Valid \\
Y21 & 0,638 & 0,658 & $\mathbf{0 , 7 6 2}$ & Valid \\
Y22 & 0,572 & 0,654 & $\mathbf{0 , 7 5 3}$ & Valid \\
Y23 & 0,439 & 0,597 & $\mathbf{0 , 7 2 9}$ & Valid \\
Y24 & 0,566 & 0,673 & $\mathbf{0 , 7 5 8}$ & Valid \\
Y25 & 0,659 & 0,696 & $\mathbf{0 , 7 4 7}$ & Valid \\
Y26 & 0,527 & 0,660 & $\mathbf{0 , 7 6 1}$ & Valid \\
Y27 & 0,700 & 0,616 & $\mathbf{0 , 7 7 8}$ & Valid \\
Y28 & 0,516 & 0,579 & $\mathbf{0 , 7 4 3}$ & Valid \\
Y29 & 0,598 & 0,627 & $\mathbf{0 , 7 9 2}$ & Valid \\
Y30 & 0,603 & 0,441 & $\mathbf{0 , 7 2 5}$ & Valid \\
Y31 & 0,456 & 0,619 & $\mathbf{0 , 7 1 3}$ & Valid \\
Y32 & 0,595 & 0,580 & $\mathbf{0 , 7 4 8}$ & Valid \\
Y33 & 0,627 & 0,600 & $\mathbf{0 , 7 4 8}$ & Valid \\
Y34 & 0,410 & 0,618 & $\mathbf{0 , 7 2 1}$ & Valid \\
Y35 & 0,730 & 0,613 & $\mathbf{0 , 7 9 3}$ & Valid \\
Y36 & 0,455 & 0,654 & $\mathbf{0 , 7 2 7}$ & Valid \\
Y37 & 0,571 & 0,642 & $\mathbf{0 , 7 7 2}$ & Valid \\
Y38 & 0,544 & 0,617 & $\mathbf{0 , 7 0 9}$ & Valid \\
Y39 & 0,639 & 0,570 & $\mathbf{0 , 7 5 6}$ & Valid \\
Y40 & 0,395 & 0,557 & $\mathbf{0 , 7 0 9}$ & Valid \\
Y41 & 0,527 & 0,615 & $\mathbf{0 , 7 2 6}$ & Valid \\
Y42 & 0,620 & 0,614 & $\mathbf{0 , 7 9 1}$ & Valid \\
Y43 & 0,551 & 0,492 & $\mathbf{0 , 7 3 2}$ & Valid \\
\hline
\end{tabular}

Sumber : Data primer diolah, 2018

Berdasarkan Tabel 6. uji discriminant validity memperlihatkan nilai korelasi cross loading indikator keadilan organisasional, kepuasaan kerja, dan komitmen organisasional dinyatakan valid.

Tabel 7.

Average Variance Extracted (AVE)

\begin{tabular}{lcc}
\hline \multicolumn{1}{c}{ Variabel } & $\begin{array}{c}\text { Average Variance Extracted } \\
\text { (AVE) }\end{array}$ & Keterangan \\
\hline Keadilan Organisasional & 0,625 & Valid \\
Kepuasan Kerja & 0,609 & Valid \\
Komitmen Organisasional & 0,560 & Valid \\
\hline
\end{tabular}

Sumber : Data primer diolah, 2018

Berdasarkan Tabel 7. hasil Average Variance Extracted (AVE) menunjukkan semua variabel dinyatakan valid.

Berdasarkan Tabel 8. hasil uji composite reliability menunjukkan bahwa nilai composite reliability semua variabel reliable. 
Tabel 8.

Composite Reliability

\begin{tabular}{lcc}
\hline \multicolumn{1}{c}{ Variabel } & Composite Reliability & Keterangan \\
\hline Keadilan Organisasional & 0,971 & Reliable \\
Kepuasan Kerja & 0,961 & Reliable \\
Komitmen Organisasional & 0,967 & Reliable \\
\hline
\end{tabular}

Sumber : Data primer diolah, 2018

Tabel 9.

$\mathbf{R}^{2}$ Variabel Latent Endogen

\begin{tabular}{lc}
\hline \multicolumn{1}{c}{ Variabel } & R Square \\
\hline Kepuasan Kerja & 0,456 \\
Komitmen Org. & 0,745 \\
\hline Sumber : Data primer diolah, 2018 &
\end{tabular}

Koefisien determinasi $R$ Square mengindikasikan bahwa komitmen organisasional dipengaruhi oleh keadilan organisasional dan kepuasan kerja sebanyak $74,5 \%$, sisanya $25,5 \%$ dipengaruhi faktor lain di luar model. Besarnya $R$ Square kepuasan kerja yaitu 45,6\% yang bermakna kepuasan kerja adalah variabel mediasi yang cukup kuat sebab dipengaruhi oleh variabel eksogen yakni keadilan organisasional sebanyak $45,6 \%$ dan sisanya $54,4 \%$ dipengaruhi oleh faktor lain di luar model. Besarnya $Q$ Square pada penelitian ini 0,647 . Hal ini bermakna $64,7 \%$ variabel eksogen dalam penelitian ini layak dipakai untuk menerangkan variabel endogen yakni komitmen organisasional.

Tabel 10.

T Statistic

\begin{tabular}{lccc}
\hline \multicolumn{1}{c}{ Variabel } & T Statistics & T Tabel & Keterangan \\
\hline Keadilan Org. $\rightarrow$ Kepuasan Kerja & 10,053 & 1.68 & Signifikan \\
Keadilan Org. $\rightarrow$ Komitmen Org. & 12,924 & 1.68 & Signifikan \\
Kepuasan Kerja $\rightarrow$ Komitmen Org. & 7,438 & 1.68 & Signifikan \\
\hline
\end{tabular}

Sumber: Data primer diolah, 2018

Berdasarkan Tabel 10. keadilan organisasional berpengaruh positif dan signifikan terhadap kepuasan kerja, keadilan organisasional berpengaruh positif dan signifikan terhadap komitmen organisasional, kepuasan kerja berpengaruh positif dan signifikan terhadap komitmen organisasional.

Tabel 11.

Path Coefficients

\begin{tabular}{lcc}
\hline \multicolumn{1}{c}{ Variabel } & Kepuasan Kerja & Komitmen Org. \\
\hline Kepuasan Kerja & & 0,560 \\
Keadilan Organisasional & 0,675 & 0,380 \\
\hline Sumber : Data primer dioh, 2018 &
\end{tabular}

Sumber : Data primer diolah, 2018 
Berdasarkan Tabel 11. hasil path coefficients mendukung hipotesis pertama yaitu keadilan organisasional berpengaruh positif dan signifikan terhadap komitmen organisasional, hipotesis kedua yaitu keadilan organisasional berpengaruh positif dan signifikan terhadap kepuasan kerja, dan hipotesis ketiga yaitu kepuasan kerja berpengaruh positif dan signifikan terhadap komitmen organisasional.

Tabel 12.

Latent Variable Correlations

\begin{tabular}{lccc}
\hline \multicolumn{1}{c}{ Variabel } & Keadilan Org. & Kepuasan Kerja & Komitmen Org. \\
\hline Keadilan Org. & 1,000 & & \\
Kepuasan Kerja & 0,675 & 1,000 & \\
Komitmen Org. & 0,758 & 0,817 & 1,000 \\
\hline
\end{tabular}

Sumber : Data primer diolah, 2018

Berdasarkan Tabel 12. dapat dilihat korelasi antara variabel. Korelasi kepuasan kerja dengan keadilan organisasional sebanyak 0,675, korelasi komitmen organisasional dengan keadilan organisasional sebanyak 0,758 , dan korelasi hubungan pada kepuasan kerja dengan komitmen organisasional sebanyak 0,817 .

Tabel 13.

Indirect Effects

\begin{tabular}{cccc}
\hline Variabel & $\begin{array}{c}\text { Koef. } \\
\text { Korelasi }\end{array}$ & T Statistics & P Value \\
\hline Kead.Org. $\rightarrow$ Kepuasan Kerja $\rightarrow$ Komit.Org & 0,378 & 6,739 & 0,000 \\
\hline
\end{tabular}

Sumber : Data primer diolah, 2018

Berdasarkan Tabel 13. dapat dijelaskan bahwa nilai $t$ Statistics lebih besar dari nilai t tabel $(6,739>1,68)$, maka kepuasan kerja secara signifikan memediasi keadilan organisasional terhadap komitmen organisasional.

Tabel 14.

\section{Signifikansi Antar Variabel}

\begin{tabular}{lc}
\hline & t Statistics \\
\hline Keadilan Org. $\rightarrow$ Kepuasan Kerja $\rightarrow$ Komitmen Org. & 6,739 \\
Keadilan Org. $\rightarrow$ Komitmen Org. & 12,924 \\
Keadilan Org. $\rightarrow$ Kepuasan Kerja & 10,053 \\
Kepuasan Kerja $\rightarrow$ Komitmen Org. & 7,438 \\
\hline Sumber $:$ Data primer diolah, 2018
\end{tabular}

Berdasarkan hasil pemeriksaan efek A, B, C, dan D, maka diperoleh hasil bahwa efek C, D, dan A signifikan yang berarti terjadi mediasi parsial pada model. Hasil ini mendukung hipotesis keempat yaitu kepuasan kerja memediasi parsial pengaruh keadilan organisasional terhadap komitmen organisasional.

Hasil memperlihatkan bahwa keadilan organisasional berpengaruh positif dan signifikan terhadap komitmen organisasional, hal ini sejalan dengan hipotesis pertama $\left(\mathrm{H}_{1}\right)$ yang menyatakan keadilan organisasional berpengaruh positif dan signifikan terhadap komitmen organisasional. Hasil penelitian ini sesuai dengan 
hasil penelitian Imran et al. (2015), Lashari et al. (2016), Mensah et al. (2016), Rahman et al. (2016), Putra dan Riana (2017), Hutagalung dan Wibawa (2018), dan Khan et al. (2018) yang menemukan keadilan organisasional berpengaruh positif dan signifikan terhadap komitmen organisasional.

Hasil memperlihatkan bahwa keadilan organisasional berpengaruh positif dan signifikan terhadap kepuasan kerja, hal ini sesuai dengan hipotesis dua $\left(\mathrm{H}_{2}\right)$ yang menyatakan keadilan organisasional berpengaruh positif dan signifikan terhadap kepuasan kerja. Hasil penelitian ini sesuai dengan hasil penelitian Altahayneh et al. (2014), Totawar dan Nambudiri (2014), Naeem et al. (2014), Hao et al. (2016), Kristanto dkk. (2014), dan Indrayani dan Suwandana (2016) yang menemukan keadilan organisasional berpengaruh positif dan signifikan terhadap kepuasan kerja.

Hasil memperlihatkan bahwa kepuasan kerja berpengaruh positif dan signifikan terhadap komitmen organisasional, hal ini sejalan dengan hipotesis tiga $\left(\mathrm{H}_{3}\right)$ yang menyatakan kepuasan kerja berpengaruh positif dan signifikan terhadap komitmen organisasional. Hasil penelitian ini sesuai dengan hasil penelitian Mohamed dan Shurbagi (2014), Awais et al. (2015), Tarigan dan Ariani (2015), Darsana dan Putra (2017), Kerisna dan Suana (2017), Yanti dan Dahlan (2017), Saputra dan Wibawa (2018), Ramadhan dan Mujiati (2018), dan Suadnyani dan Netra (2018) yang menemukan kepuasan kerja berpengaruh positif dan signifikan terhadap komitmen organisasional.

Hasil memperlihatkan bahwa kepuasan kerja memediasi parsial pengaruh keadilan organisasional terhadap komitmen organisasional, hal ini sesuai dengan hipotesis empat $\left(\mathrm{H}_{4}\right)$ yang menyatakan kepuasan kerja memediasi parsial pengaruh keadilan organisasional terhadap komitmen organisasional. Hasil penelitian ini sesuai dengan hasil penelitian Putra dan Indrawati (2018), Praditya dan Putra (2016), dan Karakus et al. (2014) yang menemukan bahwa kepuasan kerja memediasi parsial pengaruh keadilan organisasional terhadap komitmen organisasional.

Perusahaan diharapkan agar mempertahankan keadilan organisasional yang telah dilaksanakan sehingga dapat meningkatkan komitmen organisasional karyawan. Perusahaan diharapkan selalu memperhatikan suasana kerja tetap dalam kondisi yang nyaman sehingga karyawan merasa puas dan betah serta komitmen organisasional karyawan menjadi tinggi.

\section{SIMPULAN}

Berdasarkan hasil analisis yang telah diuraikan maka diperoleh simpulan yaitu Keadilan Organisasional berpengaruh positif dan signifikan terhadap Komitmen Organisasional. Hal ini bermakna semakin tinggi keadilan organisasional yang diterapkan dalam suatu perusahaan, maka semakin tinggi komitmen organisasional karyawan untuk tetap bekerja di perusahaan. Keadilan Organisasional berpengaruh positif dan signifikan terhadap Kepuasan Kerja. Hal ini bermakna semakin tinggi keadilan organisasional yang diterapkan dalam suatu perusahaan, maka semakin tinggi kepuasan kerja karyawan dalam bekerja di perusahaan. Kepuasan Kerja berpengaruh positif dan signifikan terhadap Komitmen Organisasional. Hal ini bermakna semakin tinggi kepuasan kerja karyawan dalam bekerja di perusahaan maka semakin tinggi komitmen 
organisasional karyawan untuk tetap bekerja di perusahaan. Kepuasan Kerja memediasi parsial pengaruh Keadilan Organisasional terhadap Komitmen Organisasional. Hal ini bermakna keadilan organisasional bisa menyebabkan timbulnya kepuasan kerja yang mampu memperkuat efeknya terhadap peningkatan komitmen organisasional.

Saran yang dapat diberikan terkait dengan penelitian ini yaitu dilihat dari rata-rata indikator pada variabel keadilan organisasional, nilai rata-rata terendah terdapat pada pernyataan "Pimpinan cukup adil berkaitan dengan keputusan yang dibuat terkait dengan pekerjaan saya" hal ini menunjukkan bahwa karyawan merasa pimpinan kurang adil dengan keputusan pekerjaan yang dibuat, sehingga ada baiknya pimpinan PT. Jaya Kusuma Sarana Bali lebih adil dengan keputusan pekerjaan yang dibuat untuk meningkatkan komitmen organisasional karyawannya, dilihat dari rata-rata indikator pada variabel komitmen organisasional, nilai rata-rata terendah terdapat pada pernyataan "Lebih baik apabila orang-orang bekerja di perusahaan sepanjang karier mereka" hal ini menunjukkan bahwa karyawan merasa bekerja di satu perusahaan sepanjang karier lebih baik daripada berpindah perusahaan, sehingga ada baiknya karyawan berpindah perusahaan untuk mendapatkan peluang kerja yang lebih baik, dilihat dari rata-rata indikator pada variabel kepuasan kerja, nilai rata-rata terendah terdapat pada pernyataan "Promosi sering terjadi di tempat kerja saya" hal ini menunjukkan bahwa karyawan merasa jarang adanya promosi jabatan, sehingga ada baiknya perusahaan lebih sering mengadakan promosi jabatan untuk meningkatkan kepuasan kerja karyawannya, dan peneliti selanjutnya disarankan untuk menggunakan variabel lain yang diduga mampu sebagai variabel pemediasi untuk lebih meningkatkan komitmen organisasional karyawan.

\section{REFERENSI}

Alshmemri, M., Shawan-Akl, L., \& Maude, P. (2017). Herzberg's Two-Factor Theory. Life Science Journal, 14(5), 12-16. https://doi.org/10.7537/marslsj140517.03

Altahayneh, Z. L., Khasawneh, A., \& Abedalhafiz, A. (2014). Relationship between Organizational Justice and Job Satisfaction as Perceived by Jordanian Physical Education Teachers. Asian Social Science, 10(4), 131138. https://doi.org/10.5539/ass.v10n4p131

Asriani, N. W. N., \& Supartha, I. W. G. (2017). Komitmen Organisasional Karyawan dipengaruhi oleh Iklim Organisasi dan Kepuasan Kerja pada Grand Sinar Indah Hotel. E-Jurnal Manajemen Unud, 6(11), 5999-6028.

Awais, M., Malik, M. S., \& Qaisar, A. (2015). A Review: The Job Satisfaction Act as Mediator between Spiritual Intelligence and Organizational Commitment. International Review of Management and Marketing, 5(4), 203-210.

Darsana, I. W. A., \& Putra, M. S. (2017). Pengaruh Keadilan Organisasional, 
Kepemimpinan Transformasional, dan Kepuasan Kerja terhadap Komitmen Organisasional pada Karyawan Ayodya Resort. E-Jurnal Manajemen Unud, $6(1), 146-175$.

Ghozali, I. (2016). Aplikasi Analisis Multivariate dengan Program IBM SPSS 23 (Edisi Kedelapan). Semarang: Badan Penerbit Universitas Diponegoro.

Hair Jr, J. F., Black, W. C., Babin, B. J., \& Anderson, R. E. (2010). Multivariate Data Analysis (Seventh Ed). New Jersey: Pearson Prentice Hall.

Handoko, T. H. (2014). Manajemen Personalia dan Sumber Daya Manusia (Edisi Kedua). Yogyakarta: BPFE.

Hao, Y., Hao, J., \& Wang, X. (2016). The Relationship between Organizational Justice and Job Satisfaction Evidence from China. Journal of Chinese Human Resource Management, 7(2), 115-128. https://doi.org/10.1108/JCHRM-07-2016-0012

Hutagalung, I. D. N., \& Wibawa, I. M. A. (2018). Pengaruh Keadilan Organisasional terhadap Komitmen Organisasional dan Turnover Intention Karyawan pada PT. Bank Rakyat Indonesia. E-Jurnal Manajemen Unud, 7(1), 221-250.

Ibrahim, M. E., \& Perez, A. O. (2014). Effects of Organizational Justice, Employee Satisfaction, and Gender on Employees ' Commitment : Evidence from the UAE. International Journal of Business and Management, 9(2), 45-59. https://doi.org/10.5539/ijbm.v9n2p45

Imran, R., Majeed, M., \& Ayub, A. (2015). Impact of Organizational Justice, Job Security and Job Satisfaction on Organizational Productivity. Journal of Economics, Business and Management, 3(9), 840-845. https://doi.org/10.7763/JOEBM.2015.V3.295

Indrayani, L. P. C., \& Suwandana, I. G. M. (2016). Pengaruh Keadilan Organisasional terhadap Kepuasan Kerja dan Komitmen Organisasional pada Karyawan. E-Jurnal Manajemen Unud, 5(6), 3589-3619.

Karakus, M., Ustuner, M., \& Toprak, M. (2014). Two Alternative Models on the Relationships between Organizational Justice, Organizational Commitment, Burnout, and Job Satisfaction of Education Supervisors. KEDI Journal of Educational Policy, 11(1), 69-94.

Kerisna, I. G. M. A., \& Suana, I. W. (2017). Pengaruh Kepuasan Kerja terhadap Komitmen Organisasional dan Organizational Citizenship Behavior. EJurnal Manajemen Unud, 6(7), 3962-3990. 
Khan, J. A., Sheraz, M., \& Maher, S. (2018). Impact of Organizational Justice on Organizational Commitment: Evidences From KPK Private Sector Universities. City University Research Journal, 8(2), 236-246.

Kristanto, S., Rahyuda, I. K., \& Riana, I. G. (2014). Pengaruh Keadilan Organisasional terhadap Kepuasan Kerja dan Dampaknya terhadap Komitmen, dan Intensi Keluar di PT Indonesia Power UBP Bali. E-Jurnal Ekonomi Dan Bisnis Universitas Udayana, 3(6), 308-329.

Lashari, M., Moazzam, A., Salman, Y., \& Irfan, S. (2016). Impact of Organizational Trust on Organizational Justice and Organizational Commitment: A Case of University of Sargodha. JRSP, 53(2), 170-194.

Mada, I. G. N. C. W., Sintaasih, D. K., \& Subudi, M. (2017). Pengaruh Keadilan Organisasional terhadap Motivasi dan Kinerja Karyawan. Forum Manajemen, 15(2), 1-18.

Mensah, H. K., Asiamah, N., \& Mireku, K. (2016). The Effect of Organizational Justice Delivery on Organizational Commitment Controlling for Key Confounding Variables. Journal of Global Responsibility, 7(2), 196-209. https://doi.org/10.1108/JGR-06-2016-0015

Mohamed, A., \& Shurbagi, A. (2014). The Relationship between Transformational Leadership Style Job Satisfaction and the Effect of Organizational Commitment. International Business Research, 7(11), 126138. https://doi.org/10.5539/ibr.v7n11p126

Naeem, A. T., Ihsan, F., \& Mahmood, Z. (2014). The Study of Organizational Justice, Violation of Psychological Contract and its Effect on Job Satisfaction in Paints Industry of Pakistan. International Journal of Academic Research in Business and Social Sciences, 4(12), 244-253.

Praditya, I. M. D. I., \& Putra, M. S. (2016). Pengaruh Keadilan Organisasional terhadap Kepuasan Kerja dan Komitmen Organisasional Karyawan di Wina Holiday Villa. E-Jurnal Manajemen Unud, 5(6), 3532-3559.

Putra, I. G. E. S. M., \& Indrawati, A. D. (2018). Pengaruh Keadilan Organisasi terhadap Kepuasan Kerja dan Komitmen Organisasional di Hotel Rama Phala Ubud. E-Jurnal Manajemen Unud, 7(4), 2010-2040. https://doi.org/10.24843/EJMUNUD.2018.v7.i04.p11

Putra, I. M. P. A., \& Riana, I. G. (2017). Pengaruh Keadilan Organisasional dan Keterlibatan Kerja terhadap Komitmen Organisasional pada Karyawan Bounty Hotel-Bali. E-Jurnal Manajemen Unud, 6(8), 4422-4451.

Rahman, A., Shahzad, N., Mustafa, K., Khan, M. F., \& Qurashi, F. (2016). Effects 
of Organizational Justice on Organizational Commitment. International Journal of Economics and Financial Issues, 6(3), 188-196.

Ramadhan, A. M., \& Mujiati, N. W. (2018). Pengaruh Kepemimpinan Transformasional, Keadilan Organisasional dan Kepuasan Kerja terhadap Komitmen Organisasional. E-Jurnal Manajemen Unud, 7(2), 730-758. https://doi.org/10.24843/EJMUNUD.2018.v7.i02.p07

Rejeki, A. T., \& Wulansari, N. A. (2015). Pengaruh Keadilan Organisasional pada Komitmen Organisasional dengan Kepuasan Kerja sebagai Variabel Intervening. Management Analysis Journal, 4(4), 319-326.

Robbins, S. P., \& Judge, T. A. (2015). Perilaku Organisasi (Edisi Keenam Belas). Jakarta: Salemba Empat.

Sancoko, C. A., \& Panggabean, M. S. (2015). Pengaruh Keadilan Organisasi terhadap Komitmen Organisasional dengan Kepuasan Kerja sebagai Variabel Intervening di Sekolah Santa Ursula BSD. Jurnal MIX, 5(1), 3453.

Saputra, I. M. A., \& Wibawa, I. M. A. (2018). Pengaruh Kepuasan Kerja, Keadilan Organisasional dan Pemberdayaan Karyawan terhadap Komitmen Organisasional Karyawan. E-Jurnal Manajemen Unud, 7(6), 3201-3229. https://doi.org/10.24843/EJMUNUD.2018.v7.i06.p13

Sentana, I. K. A. D., \& Surya, I. B. K. (2017). Pengaruh Kepuasan Kerja dan Komitmen Organisasional terhadap Turnover Intention. E-Jurnal Manajemen Unud, 6(10), 5232-5261.

Siagian, S. P. (2016). Manajemen Sumber Daya Manusia (Edisi Pertama). Jakarta: Bumi Aksara.

Suadnyani, D. M. L., \& Netra, I. G. S. K. (2018). Pengaruh Kepemimpinan Transformasional, Motivasi dan Kepuasan Kerja terhadap Komitmen Organisasional. E-Jurnal Manajemen Unud, 7(4), 2289-2322. https://doi.org/10.24843/EJMUNUD.2018.v7.i04.p20

Sugiyono. (2017). Metode Penelitian Bisnis Pendekatan Kuantitatif, Kualitatif, Kombinasi, dan R\&D (Edisi Ketiga). Bandung: Alfabeta.

Tarigan, V., \& Ariani, D. W. (2015). Empirical Study Relations Job Satisfaction, Organizational Commitment, and Turnover Intention. Advanced in Management \& Applied Economics, 5(2), 21-42.

Totawar, A. K., \& Nambudiri, R. (2014). Can Fairness Explain Satisfaction? Mediation of Quality of Work Life (QWL) in the Influence of 
E-Jurnal Manajemen, Vol. 8, No. 11, 2019 : 6388-6407

Organizational Justice on Job Satisfaction. South Asian Journal of Management, 21(2), 101-122.

Yanti, S., \& Dahlan, J. A. (2017). The Effects of Organizational Culture, Leadership Behavior, and Job Satisfaction on Employee Organizational Commitment. Journal of Positive Management, 8(4), 80-96. 